\title{
Development of Lactose Free Yogurt Technology for Personalized Nutrition
}

\author{
Tatiana Capcanari, Aurica Chirsanova, Eugenia Covaliov, Rodica Siminiuc \\ Department of Food and Nutrition, Faculty of Food Technology, Technical University of Moldova, Chişinău, Moldova \\ Email: tatiana.capcanari@toap.utm.md
}

How to cite this paper: Capcanari, T., Chirsanova, A., Covaliov, E. and Siminiuc, R. (2021) Development of Lactose Free Yogurt Technology for Personalized Nutrition. Food and Nutrition Sciences, 12, 1116-1135. https://doi.org/10.4236/fns.2021.1211082

Received: October 28, 2021

Accepted: November 23, 2021

Published: November 26, 2021

Copyright (อ 2021 by author(s) and Scientific Research Publishing Inc. This work is licensed under the Creative Commons Attribution International License (CC BY 4.0).

http://creativecommons.org/licenses/by/4.0/ (c) (i) Open Access

\begin{abstract}
Due to the widespread use of antibiotics, the bad ecological situation, fermented milk drinks are gaining more and more popularity because of associating with an array of health benefits. Fermented milk products contain a unique in its kind disaccharide of animal origin lactose, which has the ability to stimulate the development of lactic acid microorganisms that suppress the vital activity of pathogenic microflora in the human intestine, promoting the absorption of calcium, magnesium and phosphorus. A significant part of the world's population suffers from lactose intolerance, linked to a genetically determined deficiency of the $\beta$-galactosidase enzyme, which is one of the main reasons for the decrease in demand for dairy products among consumers suffering from primary or acquired intolerance to milk sugar. Lactose is a natural disaccharide contained in dairy products. Lactase deficiency is a variant of fermentopathy caused by the inability to break down lactose due to the activity decrease of lactase-the parietal digestion enzyme in the small intestine. Lactose intolerance in the gastrointestinal tract of a person suffering from hypo- and alactasia leads to dispersion, diarrhea and other undesirable phenomena. For the successful prevention and treatment of these diseases, it is necessary to reduce or completely eliminate the lactose intake. A technology for lactose-free milk production was developed using fermentation technology. On the basis of lactose-free milk, a range of lactose-free yoghurts was developed of animal origin of the following types: natural, enriched and fortified. Flax seeds, sesame seeds and chia seeds, which are rich in vitamins, were used to produce a range of enriched yogurts. To obtain fortified yoghurts, the mineral iron was used, which prevent the development of anemia and oncological pathologies. Experimental assortment of lactose-free yoghurts was assessed by physicochemical and organoleptic methods. All developed samples meet the standards of technical documentation for this type of food product. The organoleptic characteristics were highly appreciated. Developed lactosefree products are an opportunity for many people to return to a normal healthy
\end{abstract}


diet.

\section{Keywords}

Intolerance, Fermented Milk Products, Lactose Free, Fermentation

Technology, Healthy Diet

\section{Introduction}

Milk is an essential component of the diet of $\sim 6$ billion people. World milk production reaches 730 million tones/year [1]. Even though mammals produce milk to feed their offspring, in many parts of the world humans continue to consume milk throughout their lives. Currently, lactose intolerance is widespread throughout the world and a large part of the population does not benefit from the positive effects of milk.

Many dairy products such as yogurt, kefir, etc., have their production origins and have been consumed since ancient times. Various studies state that milk is very healthy, that it is the best source of calcium and that it prevents osteoporosis, promoting it as a real superfood. This is mostly due to its composition; the milk of any mammal has exactly the amount of protein, calcium and vitamins needed for the growth and development of their young. No other food provides all the necessary nutrients, in an ideal ratio for the body of the chicks, than milk [2].

In the years 2015-2020, the American food guides claimed that the principles of a healthy diet are based on the consumption of fat free or low-fat dairy products (1\%), including milk, yogurt, cheese, etc. However, there are people who for health reasons or based on their food preferences cannot consume dairy products. These people need to ensure their intake of nutrients (protein, calcium, potassium, magnesium, vitamin $\mathrm{D}$, and vitamin A) from products with similar compositions such as fortified products [3] [4].

Dairy products are the best source of calcium for humans. Calcium in milk and dairy products is absorbed in a higher percentage than in products of plant origin, containing certain favorable factors, such as lactose, casein and vitamin D (in the case of fortified products), thus dairy products should still be considered the superior sources of calcium [5].

Yogurt is a popular food product, appreciated for its health benefits. Since its discovery, extensive research has been conducted to understand and improve its texture, taste and properties. Consumption of yogurt has been associated in particular with the improvement of intestinal health and the immune system [6]. Today's consumers benefit from a wide variety of yoghurts available on the market [7]. Consumption of yogurt per capita has steadily increased in recent decades in most countries around the world. In the last 5 years, most developed countries have reported an increase of over $10 \%$ in sales volume [8].

Yogurt enjoys a high popularity among consumers due to the fact that it con- 
tains both Lactobacillus bulgaricus and Streptococcus thermophilus, and it is also known to contain nutrients (calcium, vitamin D and potassium) that are missing from the traditional diet [9]. Recent studies have associated the consumption of yogurt with several benefits for human health and the assimilation of certain nutrients, improved bone mineral intake, weight management, heart health, metabolic health and digestive and immune health [10]. Beneficial and special cultures can be added to yogurt and offer additional health benefits [11]. The properties of yogurt and fermented dairy products were initially investigated by Metchnikoff and highlighted their influence on human longevity, especially due to the positive effect on the intestinal flora [12].

Lactose is the main sugar in milk and dairy products, being an important source of energy for the body, but also involved in the absorption of important minerals, such as calcium or magnesium. To be used, lactose must be processed in the intestine by an enzyme called lactase that cleaves this disaccharide into glucose and galactose monomers [13]. Lactase activity is especially important during infancy, when milk is the main source of nutrition. From the eighth month of pregnancy, lactase activity can be detected on the surface of the intestinal mucosa. The activity increases until the 34th week, and at birth the lactase expression reaches its peak [14] [15]. Numerous studies have demonstrated that the ability to digest lactose during the period of breast-feeding is essential for the infant's health in order to avoid the congenital lactase deficiency that is extremely rare and fatal if not recognized very early after birth. Congenital lactose intolerance occurs when the newborn lacks the genes for lactose secretion. Missing genes appear due to defective mutations. Finally, it causes a lifelong intolerance to all types of milk, including breast milk. Physiologically, lactase has an increased activity in newborns, and its concentration will decrease over time, resulting in the primary deficiency of adult lactase (hypolactasia or non-persistence of lactase), a situation encountered in most individuals around the world. As we age, there is a progressive physiological reduction in lactase activity in the intestinal cells. It is estimated that $75 \%$ of adults worldwide suffer from a decrease in the amount of lactase produced by the body in adulthood-which is actually the normal course [16]. It has been shown that the descendants of populations that traditionally practice cattle domestication are an exception to this rule, having the ability to digest milk and other dairy products into adulthood. Figure 1 shows the frequency of "lactase persistence trait", this being higher in northern European populations, with a decreasing trend across southern Europe and the Middle East and reduced in Asia and most of Africa [17].

As a result of lactase deficiency lactose is not absorbed in the intestinal tract and leads to symptoms of lactose intolerance [18]. They are manifested by an increase in the content of intestinal water, and lactose is easily fermented by the colonic microbiome leading to the production of short-chain fatty acids and gases (mainly hydrogen $\left(\mathrm{H}_{2}\right)$, carbon dioxide $\left(\mathrm{CO}_{2}\right)$ and methane $\left(\mathrm{CH}_{4}\right)$ ) [19] [20]. 


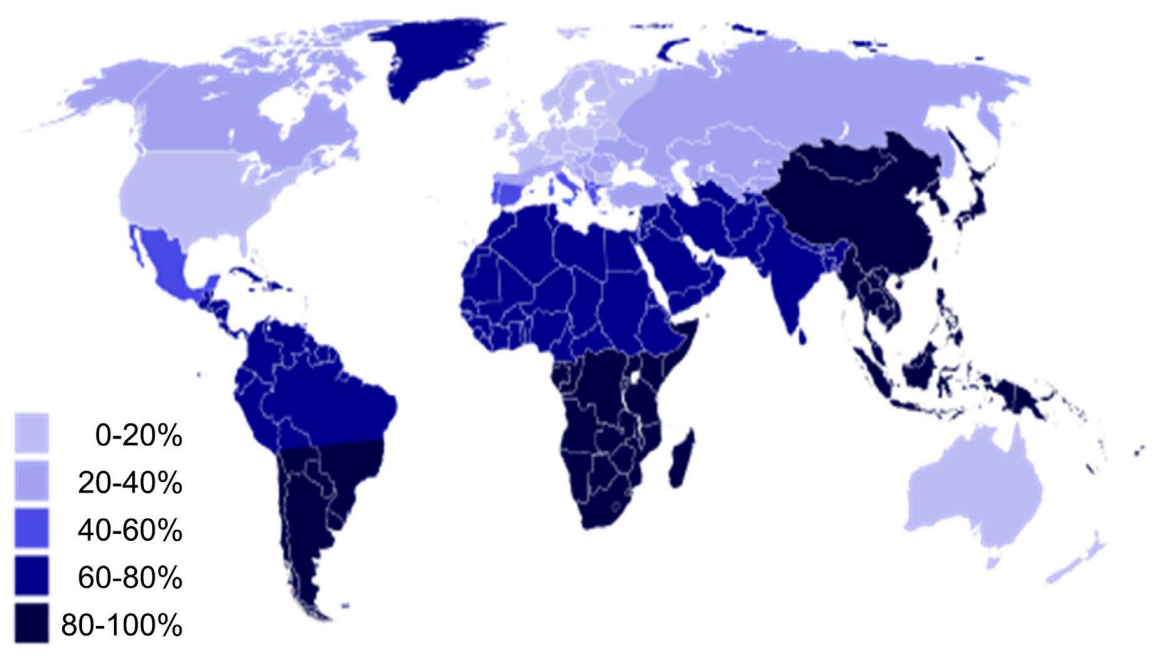

Figure 1. Lactose intolerance worldwide, \% of total population.

Lactose intolerance is a medical problem that has a significant impact on the lives of those affected. Patients report symptoms, including: abdominal pain, diarrhea, bloating, flatulence and abdominal cramps. Lactose maldigestion occurs when the concentration of the enzyme lactase is reduced at the edge of the brush of the mucosa of the small intestine. This usually occurs in early childhood. 75\% of the population is susceptible and sensitive to lactose [21]. In the Republic of Moldova, it is estimated that up to $18 \%$ of people have the potential for lactose intolerance [22] [23] [24]. Unfortunately, statistical data on consumer behavior regarding the consumption of lactose-free products, at the moment, doesn't exist [25].

In case of lactose intolerance, doctors recommend consuming alternative sources of calcium and vitamin D, either of animal origin (egg yolk, liver, fish-especially fatty), or of vegetable origin (dried beans, parsley, spinach, basil, arugula, seaweed, broccoli, almonds, hazelnuts, soy). Special preparations of lactose free milk are also recommended, as well as the consumption of calcium-rich mineral waters. However, this advice carries a significant nutritional risk.

Studies conducted between 1967 and 2009 and analyzed by the United States Department of Health and Human Services have elucidated the fact that low dietary milk and dairy intake was a risk factor for bone fracture, osteoporosis and other adverse health outcomes [26]. The study showed that dietary calcium supplements did not consistently increase bone mineral density or reduce fracture risk. Thus, research on stimulating dairy consumption while limiting the symptoms of intolerance is encouraged at international scientific forums [27]. In addition to health consequences, dairy avoidance weakens the immune system due to lack of vitamin B12, also intestinal health may suffer because the body is deprived of good bacteria and probiotics that improve intestinal health and are found in dairy products.

Studies have shown that children and adolescents who do not consume the recommended quantities of milk and milk products fail to meet their needs in 
calcium, which also impedes them to reach the peak of required bone mass. Consumption of insufficient amounts of dairy products could increase at the same time the risk of osteoporosis in elderly adults and lead to an increased risk of pathological bone fractures [28]. It was established that a nutritional diet containing insufficient amounts of vitamin $\mathrm{D}$ increases blood pressure by activating the renin-angiotensin-aldosterone system, which causes vasoconstriction as well as sodium and water retention in the body [29] [30]. Other minerals contained in dairy products, such as magnesium and potassium, might be able to regulate blood pressure, but their individual contribution is difficult to be assessed since both nutrients are usually in foods rich in calcium [31] [32]. Several studies have shown that dairy products may prevent loss of muscle mass and strength that occurs with age, as well as functional foods [33]. This phenomenon, called sarcopenia, could be prevented thanks to physical activity and a diet rich in dairy products and vitamin D [34]. The recommendations are made by The International Osteoporosis Foundation and The Society on Sarcopenia and Cachexia [35] and are based on the fact that regular use of milk products would have a positive impact on muscles, increasing skeletal muscle mass and force [36] [37], improving trabecular structure and at the same time increasing bone mineral density and bone mass [38].

As a solution for those who do not digest lactose would be the consumption of lactose-free products, which actually has the same nutritional profile as regular milk, so that they still get the same vitamins, minerals, calcium and protein, without discomfort. Over the last decade, lactose-free milk and vegetable milk have become commonplace in major supermarket chains. Sales of alternative dairy products, worth $\$ 7.37$ billion in 2016 , are projected to grow to $\$ 14.13$ billion in 2022, Dairy Reporter reports. As a consequence, lactose-free dairy is now the fastest growing market in the dairy industry. Lactose-free foods are a chance for several people to return to a traditional healthy diet [39]. Yogurts, fermented dairy products with a high mass fraction of dry matter, are gaining special popularity among the population. Therefore, it is important to expand the range of lactose-free fermented dairy products as well as animal and vegetable origin. The main aim of this work is to develop a technology for lactose-free milk produced using fermentation technology; to develop range of lactose-free yoghurts on the basis of lactose-free milk of animal origin of the following types: natural, fortified and with additives.

\section{Materials and Methods}

The yogurt was obtained in laboratory conditions of Food and Nutrition Department, Food Technology Faculty, Technical University of Moldova during January-June 2021. For the samples preparation pasteurized cow's and goat milk, starter culture YO-MIX 207 LYO containing Streptococcus thermophilus, Lactobacillus delbrueckii ssp. Bulgaricus, Lactobusillus acid Bifidobacterium lactis, Danisco, Denmark, enzyme lactase_- "Lactazic Sperco" were used. Total number 
of microorganisms from the starter culture $1.5 \times 10^{8} \mathrm{cfu} / \mathrm{ml}$ product, number of bifidobacteria $-2.5 \times 10^{7} \mathrm{cfu} / \mathrm{ml}$ product were used. In order to obtain enriched yogurt flax, sesame and chia seeds were used. Flax and sesame seeds were used as flour, chia seeds were not processed and were used in a natural form. Fortified yoghurt was obtained by mineral iron incorporation.

In the present research, the following samples of lactose-free yogurt were developed.

1) Lactose-free natural yogurt of animal origin

2) Lactose-free fortified yogurt

3) Lactose-free yogurt with additives.

Animal milk fermentation technology has been developed, which includes a process for removing lactose from milk. In order to obtain lactose-free milk, the enzyme lactase-"Lactazic Sperco" was used. Fermentation was carried out at a temperature of $37^{\circ} \mathrm{C}-38^{\circ} \mathrm{C}$. Besides taste and aroma, proper appearance and consistency are important properties. If the fermentation is prolonged or too short, the taste may suffer and the consistency will be incorrect. After primary fermentation it adds $0.5 \mathrm{ml}$ of lactase enzyme and is mixing well. Complete fermentation reaches within 2 hours. The weight of the experimental samples was $200 \mathrm{~g}$.

The technology of yogurt preparation of animal origin consists of the following steps:

1) Utensil's sterilization;

2) Animal milk fermentation;

3) Milk pasteurization at $\mathrm{f} 80^{\circ} \mathrm{C}$;

4) Milk temperation to a temperature of $37^{\circ} \mathrm{C}-39^{\circ} \mathrm{C}$;

5) Sourdough preparation (sourdough is mixing with a small portion of milk until completely dissolved);

6) The resulting starter culture is portion into milk and mixing until evenly distributed;

7) Portion the resulting milk into jars, closing them with a lid and placing for fermentation for 12 hours at a temperature of $38^{\circ} \mathrm{C}-42^{\circ} \mathrm{C}$;

8) Experimental samples of yoghurt we stored in the refrigerator for 3 - 5 days at $4^{\circ} \mathrm{C}$.

\section{Acidity}

Acidity was determined by the titrimetric method. It is based on the titration of the yogurt sample diluted with water, with $0.1 \mathrm{n}$ sodium hydroxide in the presence of phenolphthalein as indicator.

\section{$\mathrm{pH}$ measurements}

The $\mathrm{pH}$ of the samples was measured potentiometrically at $20^{\circ} \mathrm{C}$ using a $\mathrm{pH}-$ meter (HANNA 2211-02 pH/MV/C) bench meter with electrode holder.

\section{Syneresis index}

Syneresis index presents the serum separation from a clot. Whey isolation of is a consequence of the unsatisfactory quality of raw materials, deviations from 
the normal mode of homogenization and milk pasteurization. Syneresis was performed by the filtration method and measuring the amount of serum released when filtering $50 \mathrm{ml}$ of yoghurt through a paper filter within 5 hours.

\section{Protein, casein and peroxidase content}

The protein, casein and peroxidase content were performed by standard methods for the dairy products. The obtained data were compared with the standards of the Codex Alimentarius "Milk and milk products" [40] [41].

\section{Mass fraction of dry matter}

Mass fraction of dry matter was determined using standard method. The sample taken for determination is exposed to a source of heat up to a constant weight. Weight loss, calculated as a percentage, represents the moisture content, and the remaining residue-the dry matter.

\section{The glycemic index}

The glycemic index of the tested samples was determined in vivo by monitoring the blood glucose level of the experiment participants until and after the consumption of the researched food products, according to ISO 26642: 2010 [42].

\section{Sensory tests}

The methodology for analyzing the sensory quality of food products is based on the use of descriptors. This is the technical term used to define the characteristics that are perceived by the senses of taste and smell in the presence of certain compounds. Sensory tests were performed by a group of people who are taste panel trained for identifying, differentiating, and quantifying the smells and tastes. According to the objective pursued, there are four types of tests that were performed by the taste panel. Descriptive tests, which objective is to identify and quantify the descriptors of experimental samples of lactose-free yogurts; threshold flavor test, used to determine the threshold of flavor by diluting the sample with flavor-free water until the minimum perceptible flavor is achieved; discriminating tests, that enable the detection of significant differences between samples or between them and a reference sample; and acceptance tests, where the taste panel ranks or classifies the samples in terms of their preference or their level of satisfaction upon tasting them [43].

\section{Statistical Analyses}

Assays were performed in triplicate, and the results were expressed as mean values with standard deviations (SD). The significant differences represented by letters were obtained by a one-way analysis of variance (ANOVA) followed by Tukey's honestly significant difference (HSD) post hoc test $(\mathrm{p}<0.05)$. Correlations were established using Pearson's correlation coefficient $(r)$ in bivariate linear correlations $(\mathrm{p}<0.01)$. These correlations were calculated using Microsoft office Excel 2007 and SPSS version 18.0 (SPSS Inc., Chicago, IL, USA).

\section{Results and Discussions}

\section{Lactose free yogurt technology development}


Traditional yogurt making technology involved the use of boiled milk that was concentrated to two thirds of the original volume. The traditional procedure has several drawbacks: 1) the starter cultures successive inoculations tend to disorder the balance between the $S$. thermophilus and L. bulgaricus, 2) the low incubation temperature (room temperature) results in slow acidification of the milk that can create conditions for undesirable side effects; 3 ) the method does not provide control over the lactic acid level. With improved methods of yogurt production these problems do not arise [44]. Modern technologies allow monitoring of temperature, $\mathrm{pH}$ and acidity levels throughout the entire manufacturing process. Thus, the cooling of the mixture and the cessation of fermentation, respectively, is done when these parameters reach the desired values, thus allowing the standardization of the yogurt quality [45].

The essential microflora of yogurt which is obtained from commercial starter manufacturers or starter banks consists of the thermophilic lactic bacteria Streptococcus thermophilus and Lactobacillus delbrueckii ssp. Bulgaricus. In order to form a satisfactory aroma, the two species must be in approximately equal proportions, developing through protooperation (mutual stimulating influence) [46].

Most often the classification of yogurt is made according to: 1) The used raw material (cow's milk; sheep's milk; buffalo's milk); 2) the fat content (Dietary yogurt $0.1 \%-1 \%$ fat; Fatty yogurt $1 \%-3 \%$ fat; Extra yogurt $3 \%-4.4 \%$ fat; Special yogurt $6 \%-7 \%$ fat); and 3 ) the used flavor (natural yogurt, cereal, fruit: fruit pulp or fruit flavor, vanilla, chocolate, etc.) [47]. This is not true everywhere, the US has standards of identity that specify what ingredients can be used in yogurt. The fat content classification is used in compositional standards to facilitate standardization of product and to protect the consumer [48]. In recent years, worldwide production of yogurt has increased greatly as a result of improved manufacturing technology, improved packaging conditions and diversification of presentation, as well as the manufacture of new assortments with different ingredients and flavors. All this makes the product more attractive, satisfying the different preferences of consumers [49]. Based on the manufacture technology and physical structure of the coagulum there are two main types of yogurts are set and stirred. Set yogurt is thermostated and cooled in packaging after dosing, on the other hand stirred yogurt is coagulated in tanks and cooled before packing. Fluid yogurt may be considered as stirred yogurt of low viscosity. However, traditionally, fluid yogurt is manufactured by m1xtng equal quantities of yogurt and water and one of the main characteristics of such a product is the separation of the solid and the whey phases. Hence, it is customary to shake the product before consumption [50].

Lactose free natural, fortified and with additives yogurt technology development of animal origin

Due to the fact that the market segment is not very familiar with the assortment of lactose-free yoghurt and their assortment is minimal, a range of new lactose-free products was developed in order to familiarize and increase the range 
of these types of products.

For the study, 7 samples of yoghurts of animal origin were prepared in a laboratory condition, in the quality of control sample unfermented cow's milk yogurt with lactose was used. The milk was warmed up to a temperature of $37^{\circ} \mathrm{C}$ $38^{\circ} \mathrm{C}$, the enzyme lactase (Lactazik) was added to remove lactose from the milk and the starter culture. Recipes for experimental samples of lactose-free yogurts are presented in Table 1.

Table 1. Recipes for experimental samples of lactose-free yogurts this should be in materials and methods.

\begin{tabular}{|c|c|c|c|c|c|c|}
\hline Sample & Product code* & Milk, 1 & Enzyme, $\mathrm{g}$ & Additives, $\mathbf{g}$ & $\begin{array}{c}\text { Ferment } \\
\text { lactase, } \mathrm{ml}\end{array}$ & Photo \\
\hline \multicolumn{7}{|c|}{ Natural yogurt } \\
\hline $\begin{array}{l}\text { Unfermented } \\
\text { cow's milk yogurt }\end{array}$ & Control sample CS & 0.2 & 0.2 & - & - & \\
\hline $\begin{array}{c}\text { Lactose-free } \\
\text { cow's milk yogurt }\end{array}$ & LFNC & 0.2 & 0.2 & - & 0.5 & \\
\hline $\begin{array}{c}\text { Lactose-free } \\
\text { goat's milk yogurt }\end{array}$ & LFNG & 0.2 & 0.2 & - & 0.5 & \\
\hline
\end{tabular}

\section{Enriched yogurts}

Lactose-free cow's milk yogurt with flax seeds

Lactose-free cow's milk yogurt with sesame seeds

LFESS yogurt with chia seeds
0.2

0.2

0.2

0.2

0.2

0.2

25

10

Fortified yogurt

0.2

0.2
0.5

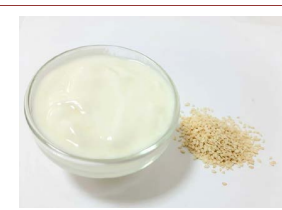

0.5

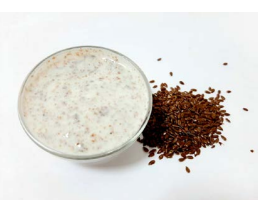

Lactose-free cow's milk yogurt fortified with iron

LFFIR

0.5

0.5

${ }^{\star} \mathrm{CS}$-control sample, LF-lactose free, $\mathrm{N}$-natural, E-enriched, F-fortified, C-cow's milk, G-goat milk, FS—flax seeds, SS— sesame seeds, CS—chia seeds, IR-iron. 
Flax, sesame and chia seeds were used to obtain enriched yogurts. This assortment of seeds was not chosen by chance. These seeds are a reservoir of nutritional components with numerous beneficial effects along with health promotion in humans [51]. The seeds are rich in vital minerals, vitamins, phytosterols, polyunsaturated fatty acids, tocopherols which are bioactive substances. It is worth mentioning that they are an important source of plant protein, vitamin B1, dietary fiber, as well as an excellent source of phosphorus, iron, magnesium, calcium, manganese, copper and zinc [52]. In addition to these important component's sesame seeds contain unique substances-sesame and sesamolin, which are dietary fiber from the group of lignans, which have a cholesterol-lowering effect, prevent high blood pressure, increase the absorption of vitamin E [53]. Iron deficiency anemia is caused by low iron intake from the diet or certain physiological states of malnutrition of this element and the body does not produce enough erythrocytes. This physiological condition rarely leads to death, but is linked to several health problems. This disease is easily identified and treated, but is not taken into account by doctors. Iron deficiency anemia has a significant impact on health and affects large sections of the population in underdeveloped countries [54] [55].

Overall, the prevention and successful treatment for iron deficiency anemia remains woefully insufficient worldwide, especially among underprivileged families, women and children, such an astringent problem of the Republic of Moldova.

The frequency of iron deficiency anemia in the Republic of Moldova is high, being detected in certain population groups, such as women of childbearing age (especially pregnant women), young children and adolescents. From the groups of elderly people, vegetarians, people with a poor socio-economic level, as well as and people suffering from certain chronic conditions. Studies conducted in the Republic of Moldova show that in some population groups the range of products used does not cover the physiological need of the body in iron. In this context it is necessary to mention that the approached topic is extremely important. The assortment of iron-fortified lactose-free dairy products in the Republic of Moldova generally does not exist.

Quality indices evaluation of the experimental assortment of lactose-free yogurts

Experimental samples were subjected to research in terms of physicochemical and organoleptic indicators. According to Codex Alimentarius "Milk and milk products" yoghurt in terms of organoleptic and physicochemical indicators must meet certain requirements [40] [41].

In this research of physicochemical parameters evaluation of lactose-free yoghurts, the following parameters were investigated: titratable acidity, mass fraction of dry substances, mass fraction of protein, peroxidase, syneresis, $\mathrm{pH}$. These indicators are determining the quality of yoghurt. In terms of physical and chemical indicators, yoghurts must meet the standards specified in Table 2. 
Table 2. Physico-chemical quality indices standards of yogurt [40] [41].

\begin{tabular}{lc}
\multicolumn{1}{c}{ Quality indicator } & Normative \\
\hline Protein content, \%, not less than: & 3.2 \\
- for yoghurts without additives & $2.8^{*}$ \\
- for enriched yoghurts & \\
Dry matter content, \%, not less than: & 9.5 \\
- for yoghurts without additives & 8.5 \\
- for enriched yoghurts & From 75 to 140 \\
Acidity, ${ }^{\circ} \mathrm{T}$ & $4-5$ \\
pH & absent \\
Peroxidase &
\end{tabular}

The titratable acidity and $\mathrm{pH}$ of yogurt have a great sensory and prebiotic importance-they directly influence the development and viability of probiotic microorganisms. The evolution of titratable acidity and $\mathrm{pH}$ is correlated with the intensity of lactic fermentation.

During fermentation, the reducing carbohydrates are fermented rapidly. As a result, acid lactic accumulates. The process of lactic acid accumulation is accompanied by an increase in acidity [56].

Lactose degradation begins immediately after adding starter culture and continue during the thermostat period. Both the International Milk Federation and the Technical Regulations of the Republic of Moldova "Milk and dairy products" specifies a minimum acidity of $0.6 \%$ lactic acid in yogurt for sale [57]. The recommended value is found in all yogurt samples studied at the end of the thermostat period. The accumulation of lactic acid contributes to the formation of a more pronounced flavor of yogurt. The dynamics of the acidity index in experimental yogurts of animal origin is shown in Figure 2.

Thus, in the experimental samples of lactose-free yogurt, the acidity was determined for 5 hours after preparation. Compared to the control sample, the acidity in lactose-free yogurts is higher, but in the acceptable range.

All the results were within the normal range. This is explained by the fact that in the production of this yogurt, the technological process was followed and highquality raw materials were used. The highest titratable acidity was found in natural yogurt made from goat's milk, which was $140^{\circ} \mathrm{T}$, this is explained by the fact that lactic acid bacteria have the ability to ferment lactose into lactic acid, which leads to an increase in titratable acidity.

The lowest indicative titratable acidity was found in fortified lactose-free yogurt from cow's milk with chia seeds, which was $108^{\circ} \mathrm{T}$. Thus, natural yoghurt samples showed the highest acidity values, and in enriched samples the acidity decrease.

The $\mathrm{pH}$ evolution is correlated with the intensity of lactose fermentation and the increase of titratable acidity, but it is also influenced by the buffers that are 


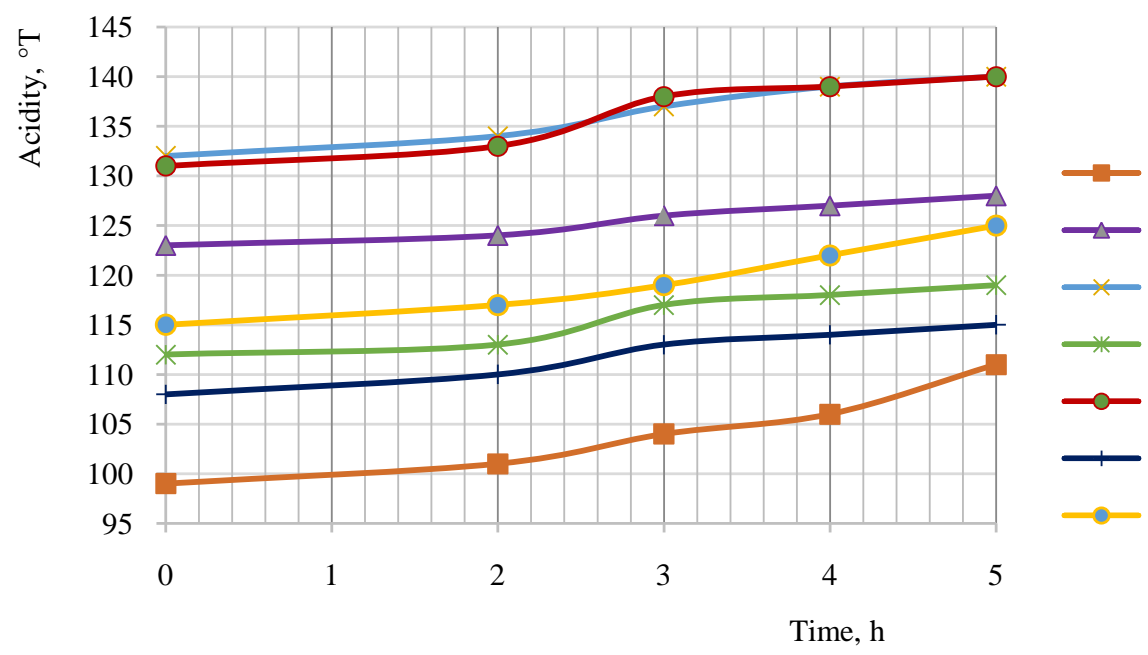

Figure 2. The acidity index evolution in experimental yogurts of animal origin.

found in added seeds or are formed during manufacture. $\mathrm{Ph}$ was determined in fresh samples within 5 hours, Figure 3.

In the maturation process, in all samples of yogurts without lactose $\mathrm{pH}$ increased, but not significantly. By the end of the maturation process it reached values of $4.0-4.37$.

The structure and rheological properties of fermented dairy products are influenced by a number of factors: milk quality, $\mathrm{pH}$, nature of bacterial cultures, temperature, mechanical processing, fermentation time, the presence of additives. The rheological properties are characterized by the index of syneresis and viscosity. Syneresis is a complex biochemical and physico-chemical phenomenon, and represents a thermodynamic property of gels which consists in the decrease of the gel volume, caused by the expulsion of a quantity of solvent with its maturation [58]. The intensity and depth of the yoghurt syneresis depends largely on the internal surface of the solid phase, the porosity (spaces occupied by the whey) and the permeability of the gel.

The syneresis index was determined in the dynamics within 5 hours. The values of the syneresis index were determined by the method described by Merculov. The largest amount of serum is eliminated within 2 hours, and then the amount of serum decreases. This can be explained by the fact that the hardness of the clot decreases every hour, Figure 4.

Analyzing the dynamics of the syneresis index, it was found that the highest amount of whey was released in yogurt from cow's milk $6.5 \mathrm{ml}$, and the lowest amount of goat's milk $1 \mathrm{ml}$, this is explained by the fact that in yogurt in goat's milk the curd was harder than in cow's milk yogurt. Compared to the control sample, less serum was released in the lactose-free yogurt samples than in the control sample, but all samples comply with the regulations. The release of serum up to $10 \mathrm{ml}$ from the volume of the product is within the permissible limits for those products.

Casein is protein, which together with whey is obtained from milk from 


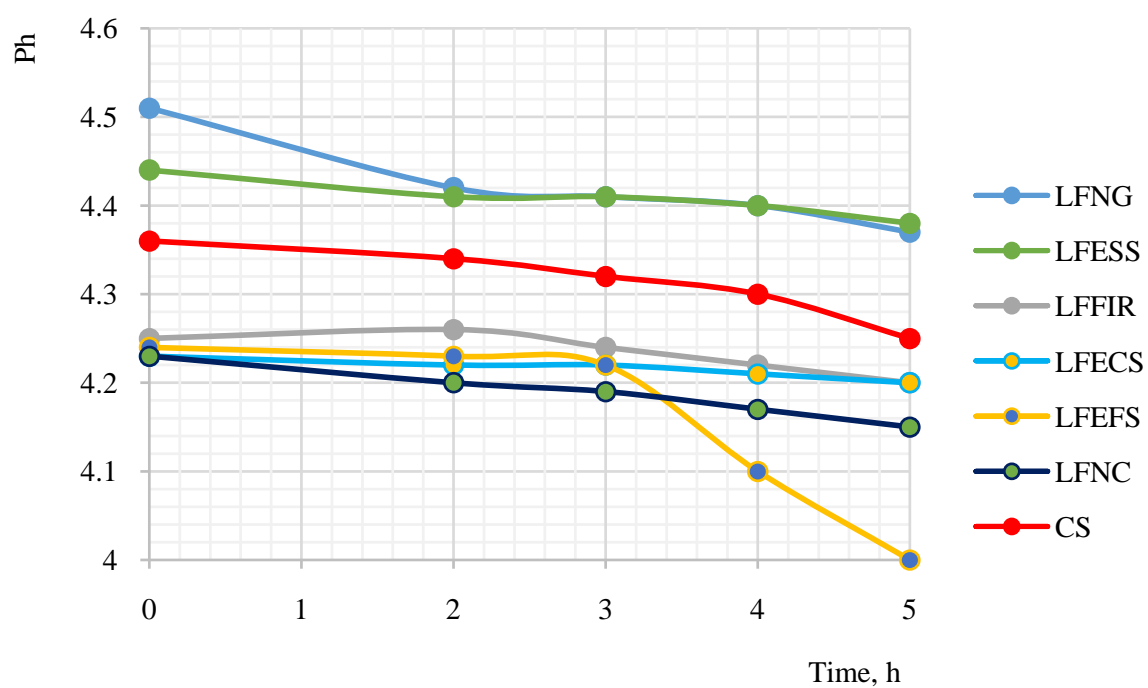

Figure 3. The $\mathrm{pH}$ evolution of the lactose-free yogurt samples.

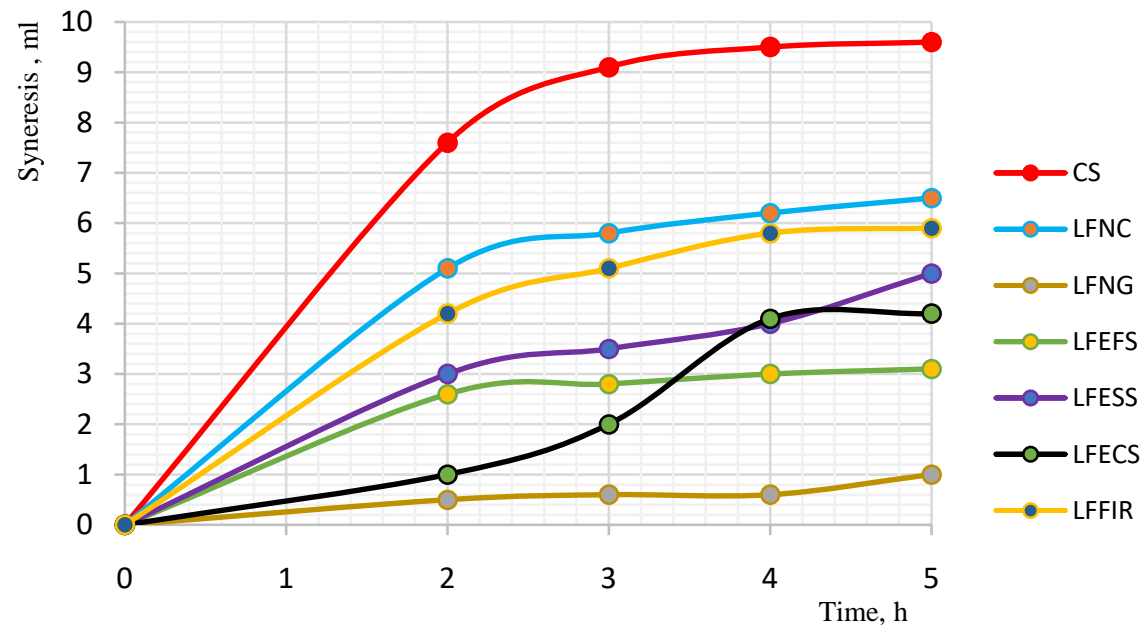

Figure 4. The syneresis index dynamics.

mammals. Most people consume casein in the form of cow's milk. It is an insoluble part of milk, which represents about $80 \%$ of milk proteins. The soluble part of the milk and the remaining $20 \%$ is whey. In the present paper, the content of protein, casein, peroxidase and dry matter in the experimental samples was determined, Table 3.

The determination of these parameters demonstrated an important protein (in a range of $4.22 \pm 0.08 \mathrm{~g}$ to $6.04 \pm 0.12 \mathrm{~g}$ ) and casein (in a range of $2.69 \pm 0.05$ $\mathrm{g}$ to $3.84 \pm 0.08 \mathrm{~g}$ ) content in the experimental samples. These demonstrate the high quality of the yogurts obtained that can be recommended to patients with lactose intolerance, but also to other categories of the population.

All yoghurt samples were tested for the presence of peroxidase in it. The determination of peroxidase determines the temperature of milk pasteurization during preparation of the test samples of yoghurt. In all the studied samples of yoghurt, the presence of peroxidase was not detected, which proves that all samples 
Table 3. Protein, casein, peroxidase and dry matter content in experimental samples of lactose-free yogurt.

\begin{tabular}{ccccc}
\hline Sample & Protein, g & Casein, g & Peroxidase & Dry matter content, \% \\
\hline CS & $4.63 \pm 0.29^{\mathrm{c}}$ & $3.07 \pm 0.19^{\mathrm{f}}$ & absent & $8.82 \pm 0.52^{\mathrm{g}}$ \\
LFNC & $4.53 \pm 0.15^{\mathrm{b}}$ & $3.01 \pm 0.10^{\mathrm{d}}$ & absent & $8.47 \pm 0.21^{\mathrm{b}}$ \\
LFNG & $6.04 \pm 0.12^{\mathrm{a}}$ & $3.84 \pm 0.08^{\mathrm{a}}$ & absent & $11.27 \pm 0.25^{\mathrm{e}}$ \\
LFEFS & $5.28 \pm 0.10^{\mathrm{d}}$ & $3.36 \pm 0.07^{\mathrm{c}}$ & absent & $11.15 \pm 0.15^{\mathrm{g}}$ \\
LFESS & $4.22 \pm 0.08^{\mathrm{f}}$ & $2.69 \pm 0.05^{\mathrm{b}}$ & absent & $14.20 \pm 0.19^{\mathrm{c}}$ \\
LFECS & $4.53 \pm 0.09^{\mathrm{a}}$ & $2.88 \pm 0.06^{\mathrm{e}}$ & absent & $12.38 \pm 0.33^{\mathrm{d}}$ \\
LFFIR & $4.53 \pm 0.10^{\mathrm{g}}$ & $2.88 \pm 0.05^{\mathrm{c}}$ & absent & $9.87 \pm 0.51^{\mathrm{a}}$
\end{tabular}

Note: a-g: in each column different letters mean significant differences $(\mathrm{p}<0.05)$.

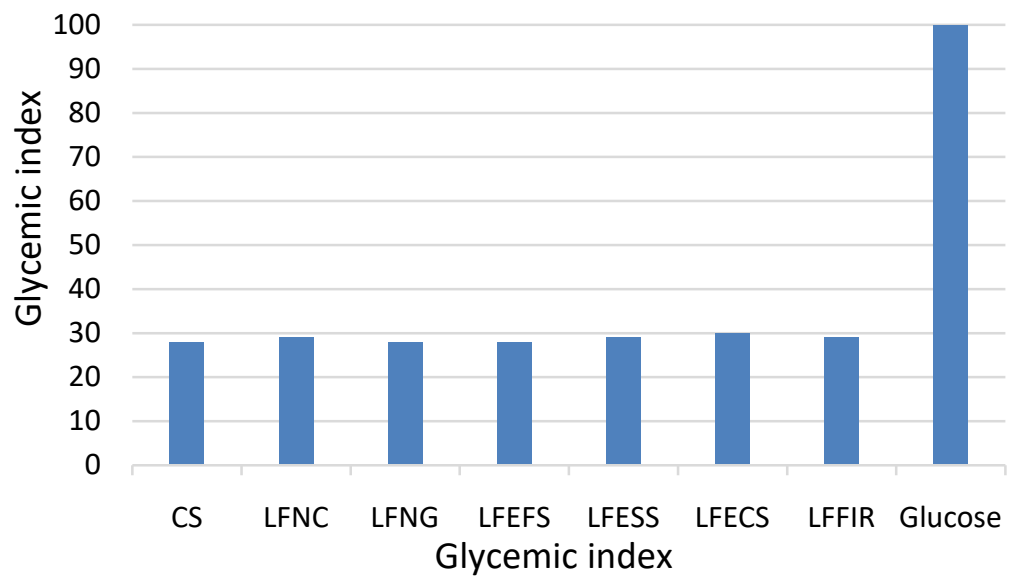

Figure 5. Glycemic index of experimental samples of lactose-free yogurts.

of yoghurt were subjected to pasteurization at a temperature not lower than $80^{\circ} \mathrm{C}$ and the technological process was not disturbed. The dry matter content varied in a range of $8.47 \% \pm 0.21 \%$ to $14.20 \% \pm 0.19 \%$. Enriched yoghurts have higher rates due to the seeds components.

Several studies have shown that a diet with a high glycemic index is associated with an increased risk of developing type 2 diabetes, cardiovascular disease, some cancers and others [59].

Experimental results showed that the glycemic index of the elaborated yogurts are in the range of 28 - 30 and are quite close, Figure 5 . The additives used in the developed technology did not essentially influence the glycemic index due to the fact that the raw materials used are with low glycemic index. Thus, according to international data and recommendations in the field we can say that elaborated yogurts can be included in the category of foods with low glycemic index and can be recommended in diets that reduce the risk of type 2 diabetes, cardiovascular disease for people with lactose intolerance [60].

Quality control of food products is associated with the analysis of different parameters, and organoleptic characteristics [61]. Experimental data of sensory tests of elaborated samples of lactose-free yogurts are presented in Figure 6. 


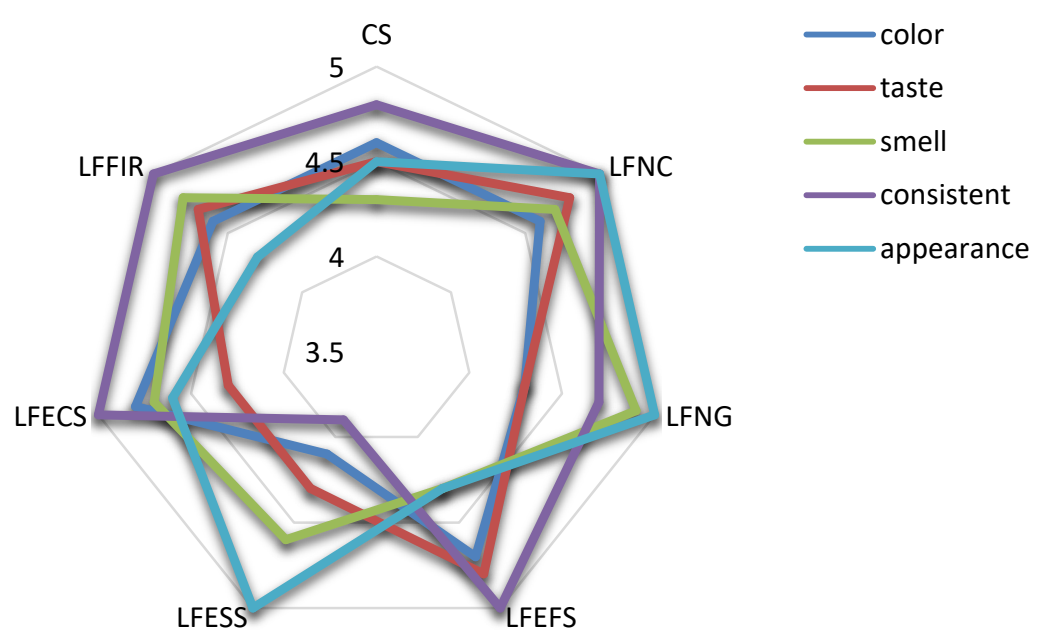

Figure 6. Sensory tests of experimental samples of lactose-free yogurts.

All experimental samples showed the high organoleptic characteristics. Punctuation varying from 3.9 to 5.0. Samples have a characteristic milky taste without foreign odors. The consistency corresponds to the given product.

\section{Conclusions}

As a result of physicochemical research of the developed lactose-free yogurt, it was revealed that all parameters are in accordance with the regulatory documentation, is within acceptable limits for lactose-free yoghurts of animal origin.

It has been found that experimental samples are an important source of protein, especially casein, which demonstrates the high quality of obtained yogurts that can be recommended to patients with lactose intolerance, but also to other categories of the population. The glycemic index found after the consumption of natural, fortified and yogurt with additive's, denotes that these products fall into the category of "dairy products with low glycemic index".

It was obtained maximum score for organoleptic indices of experimental samples, which indicates that the developed products will be attractive to consumers.

\section{Acknowledgements}

The research was funded by State Project 20.80009.5107.10, nr. PS-62 "Personalized nutrition and intelligent technologies for my well-being", running at Technical University of Moldova.

\section{Conflicts of Interest}

The authors declare no conflicts of interest regarding the publication of this paper.

\section{References}

[1] FAO (2020) Dairy Market Review: Emerging Trends and Outlook. Food and Agriculture Organization of the United Nations, Rome. 
http://www.fao.org/3/cb2322en/CB2322EN.pdf

[2] Visioli, F. and Strata, A. (2014) Milk, Dairy Products, and Their Functional Effects in Humans: A Narrative Review of Recent Evidence. Advances in Nutrition, 5, 131143. https://doi.org/10.3945/an.113.005025

[3] Weaver, C.M. (2014) Calcium Supplementation: Is Protecting against Osteoporosis Counter to Protecting against Cardiovascular Disease? Current Osteoporosis Reports, 12, 211-218. https://doi.org/10.1007/s11914-014-0208-1

[4] Bolland, M.J., Grey, A. and Reid, I.R. (2013) Calcium Supplements and Cardiovascular Risk: 5 Years on. Therapeutic Advances in Drug Safety, 4, 199-210.

https://doi.org/10.1177/2042098613499790

[5] Astrup, A. (2014) Yogurt and Dairy Product Consumption to Prevent Cardiometabolic Diseases: Epidemiologic and Experimental Studies. The American Journal of Clinical Nutrition, 99, 1235S-1242S. https://doi.org/10.3945/ajcn.113.073015

[6] He, A., Chin, J. and Lomiguen, C.M. (2020) Benefits of Probiotic Yogurt Consumption on Maternal Health and Pregnancy Outcomes: A Systematic Review. Cureus, 12, e9408. https://doi.org/10.7759/cureus.9408

[7] Barengolts, E., Smith, E.D., Reutrakul, S., Tonucci, L. and Anothaisintawee, T. (2019) The Effect of Probiotic Yogurt on Glycemic Control in Type 2 Diabetes or Obesity: A Meta-Analysis of Nine Randomized Controlled Trials. Nutrients, 11, Article No. 671. https://doi.org/10.3390/nu11030671

[8] Chandan, C.R., Gandhi, A. and Shah, P.N. (2017) Yogurt: Historical Background, Health Benefits, and Global Trade. In: Shah, N.P., Ed., Yogurt in Health and Disease Prevention, Academic Press, Cambridge, 3-29. https://doi.org/10.1016/B978-0-12-805134-4.00001-8

[9] Nikooyeh, B., Hollis, B.W. and Neyestani, T.R. (2021) The Effect of Daily Intake of Vitamin D-Fortified Yogurt Drink, with and without Added Calcium, on Serum Adiponectin and Sirtuins 1 and 6 in Adult Subjects with Type 2 Diabetes. Nutrition \& Diabetes, 11, Article No. 26.

[10] Michels, K.B., Willett, W.C., Vaidya, R., Zhang, X. and Giovannucci, E. (2020) Yogurt Consumption and Colorectal Cancer Incidence and Mortality in the Nurses' Health Study and the Health Professionals Follow-Up Study. The American Journal of Clinical Nutrition, 112, 1566-1575. https://doi.org/10.1093/ajcn/nqaa244

[11] Freitas, M. (2017) The Benefits of Yogurt, Cultures, and Fermentation. In: Floch, M.H., Ringel, Y. and Walker, W.A., Eds., The Microbiota in Gastrointestinal Pathophysiology, Academic Press, Cambridge, 209-223. https://doi.org/10.1016/B978-0-12-804024-9.00024-0

[12] Bonavina, L., Arini, A., Ficano, L., et al. (2019) Abincol ${ }^{\circledR}$ (Lactobacillus plantarum LP01, Lactobacillus lactis subspecies cremoris LLC02, Lactobacillus delbrueckii LDD01), an Oral Nutraceutical, Pragmatic Use in Patients with Chronic Intestinal Disorders. Acta Biomedica, 90, 8-12.

[13] Katoch, G.K., Nain, N., Kaur S. and Rasane, P. (2021) Lactose Intolerance and Its Dietary Management: An Update. Journal of the American College of Nutrition, 1-11. https://doi.org/10.1080/07315724.2021.1891587

[14] Szabó, E., Szakos, D. and Kasza, G. (2021) Analysis of the Target Group of Lactose-Free Functional Foods for Product Development. Acta Alimentaria, 50, 153-161. https://doi.org/10.1556/066.2020.00168

[15] Popovici, V., Radu, O., Hubenia, V., Covaliov, E., Capcanari, T. and Popovici, C. (2019) Physico-Chemical and Sensory Properties of Functional Confectionery Products with Rosa Canina Powder. Ukrainian Food Journal, 8, 815-827. 
http://ufj.ho.ua/Archiv/UKRAINIAN\%20FOOD\%20JOURNAL\%202019\%20V.8\%2 OIs.4.pdf

[16] Di Costanzo, M., Biasucci, G., Maddalena, Y., Di Scala, C., De Caro, C., Calignano, A. and Canani, R.B. (2021) Lactose Intolerance in Pediatric Patients and Common Misunderstandings About Cow's Milk Allergy. Pediatric Annals, 50, e178-e185.

[17] Catanzaro, R., Sciuto, M. and Marotta, F. (2021) Lactose Intolerance-Old and New Knowledge on Pathophysiological Mechanisms, Diagnosis, and Treatment. SN Comprehensive Clinical Medicine, 3, 499-509. https://doi.org/10.1007/s42399-021-00792-9

[18] Swallow, D.M. (2003) Genetics of Lactase Persistence and Lactose Intolerance. Annual Review of Genetics, 37, 197-219.

https://doi.org/10.1146/annurev.genet.37.110801.143820

[19] Gasbarrini, A., Corazza, G.R., Gasbarrini, G., Montalto, M., di Stefano M., Basilisco, G., Parodi, A., Usai-Satta, P., Vernia, P., Anania, C., et al. (2009) Methodology and Indications of $\mathrm{H}_{2}$-Breath Testing in Gastrointestinal Diseases: The Rome Consensus Conference. Alimentary Pharmacology \& Therapeutics, 29, 1-49.

https://doi.org/10.1111/j.1365-2036.2009.03951.x

[20] Magge, S. and Lembo, A. (2012) Low-FODMAP Diet for Treatment of Irritable Bowel Syndrome. Gastroenterology \& Hepatology, 8, 739-745.

[21] Shepherd, S.J., Lomer, M.C. and Gibson, P.R. (203) Short-Chain Carbohydrates and Functional Gastrointestinal Disorders. American Journal of Gastroenterology, 108, 707-717. https://doi.org/10.1038/ajg.2013.96

[22] Boaghi, E., Capcanari, T., Mija, N., Deseatnicova, O. and Opopol, N. (2018) The Evolution of Food Products Consumption in Republic of Moldova in the Demographic Transition Period. Journal of Engineering Science, 25, 74-81.

https://jes.utm.md/wp-content/uploads/sites/20/2019/03/JES-2018-4 74-81.pdf

[23] Chirsanova, A., Capcanari, T., Boistean, A., Covaliov, E., Resitca, V. and Sturza, R. (2020) Behavior of Consumers in the Republic of Moldova Related to the Consumption of Trans Fat. International Journal of Food Science, Nutrition and Dietetics, 9, 493-498.

[24] Chirsanova, A., Covaliov, E., Capcanari, T., Suhodol, N., Deseatnicova, O., Boistean, A., Resitca, V. and Sturza, R. (2020) Consumer Behavior Related to Salt Intake in the Republic of Moldova. Journal of Social Sciences, 3, 101-110. https://jss.utm.md/wp-content/uploads/sites/21/2021/01/JSS-4-2020-pp 101-110.pdf

[25] Cazacu, V. (2021) European Union Food Security Policy: Impact on Food Security of the Republic of Moldova in the Context of the Association Agreement. InterConf. https://ojs.ukrlogos.in.ua/index.php/interconf/article/view/10808/10168

[26] Brannon, P.M., Carpenter, T.O., Fernandez, J.R., et al. (2010) NIH Consensus Development Conference Statement: Lactose Intolerance and Health. NIH Consensus and State-of-the-Science Statements, 27, 1-27.

[27] Amini, M., Sepehrimanesh, M., Vafa, L. and Poorbaghi, S. L. (2019) The First Report about the Laparoscopic Sleeve Gastrectomy-Induced Lactose Intolerance. $O b$ esity Surgery, 29, 1081-1082. https://doi.org/10.1007/s11695-018-03694-3

[28] Zaitlin, P., Dwyer, J. and Gleason, G. (2013) Mistaken Beliefs and the Facts about Milk and Dairy Foods. Nutrition Today, 48, 135-143. https://doi.org/10.1097/NT.0b013e3182941c62

[29] Heyman, M. (2006) Lactose Intolerance in Infants, Children and Adolescents. Pediatrics, 118, 1279-1286. https://doi.org/10.1542/peds.2006-1721

[30] Radavelli-Bagatini, S., Zhu, K., Lewis, J. and Prince, R. (2014) Dairy Food Intake 
Peripheral Bone Structure, and Muscle Mass in Elderly Ambulatory Women. Journal of Bone and Mineral Research, 29, 1691-1700. https://doi.org/10.1002/jbmr.2181

[31] Chirsanova, A., Capcanari, T. and Gîncu, E. (2021) Jerusalem Artichoke (Helianthus tuberosus) Flour Impact on Bread Quality. Journal of Engineering Science, 28, 131-143. https://doi.org/10.52326/jes.utm.2021.28(1).14

[32] Radavelli-Bagatini, S., Zhu, K., Lewis, J., Dhaliwal, S. and Prince, R. (2013) Association of Dairy Intake with Body Composition and Physical Function in Older Community-Dwelling Women. Journal of the Academy of Nutrition and Dietetics, 113, 1669-1674. https://doi.org/10.1016/j.jand.2013.05.019

[33] Alemán-Mateo, H., Macías, L., Esparza-Romero, J., Astiazaran-García, H. and Blancas, A. (2012) Physiological Effects beyond the Significant Gain in Muscle Mass in Sarcopenie Elderly Men: Evidence from a Randomized Clinical Trial Using a Protein-Rich Food. Clinical Interventions in Aging, 7, 225-234.

https://doi.org/10.2147/CIA.S32356

[34] Popovici, V., Covaliov, E., Capcanari, T., Popovici, C. and Radu, O. (2019) Evolution of Total Carotenoid Content in Food Products Enriched with Rosehip (Rosa Canina) Powder. Resource and Energy Saving Technologies of Production and Packing of Food Products as the Main Fundamentals of Their Competitiveness. Proceedings of the 8th International Specialized Scientific and Practical Conference, Kyiv, 12 September 2019.

[35] Birnie, K., Ben-Shlomo, Y., Gunnell, D., Ebrahim, S., Gallacher, J., Jeff, M. and Holly, P. (2012) Childhood Milk Consumption Is Associated with Better Physical Performance in Old Age. Age and Ageing, 41, 776-784. https://doi.org/10.1093/ageing/afs052

[36] Romero-Velarde, E., Delgado-Franco, D., García-Gutiérrez, M., Gurrola-Díaz, C., Larrosa-Haro, A., Montijo-Barrios, E., et al. (2019) The Importance of Lactose in the Human Diet: Outcomes of a Mexican Consensus Meeting. Nutrients, 11, Article No. 2737. https://doi.org/10.3390/nu11112737

[37] Greco, E.A., et al. (2019) Osteoporosis and Sarcopenia Increase Frailty Syndrome in the Elderly. Frontiers in Endocrinology, 10, Article No. 255.

https://doi.org/10.3389/fendo.2019.00255

[38] Dabija, A., Codină, G.G., Gâtlan, A.M. and Rusu, L. (2018) Quality Assessment of Yogurt Enriched with Different Types of Fibers. CyTA-Journal of Food, 16, 859-867. https://doi.org/10.1080/19476337.2018.1483970

[39] Dekker, P.J.T., Koenders, D. and Bruins, M.J. (2019) Lactose-Free Dairy Products: Market Developments, Production, Nutrition and Health Benefits. Nutrients, 11, Article No. 551. https://doi.org/10.3390/nu11030551

[40] WHO and FAO (2011) Milk and Milk Products. The Codex Alimentarius Commission, Rome. http://www.fao.org/3/i2085e/i2085e00.pdf

[41] AOAC (1990) Official Methods of Analysis. 15th Edition, Association of Official Analytical Chemists, Arlington, VA.

[42] ISO 26642:2010 Food Products-Determination of the Glycaemic Index (GI) and Recommendation for Food Classification. Technical Committee: ISO/TC34 Food Products, $18 \mathrm{p}$.

[43] Guvernul Republicii Moldova (2010) Hotărîre Nr. 611 din 05-07-2010. https://www.legis.md/cautare/getResults?doc id=22246\&lang=ro

[44] Celik, O.F. and Temiz, H. (2020) Traditional Yogurt Dilemma; Rich Flavor vs. Microbial Safety: An Investigation on Volatile Aroma Profiles, Chemical, and Microbiological Qualities of Traditional Yogurts. Journal of Central European Agriculture, 
21, 461-475. https://doi.org/10.5513/JCEA01/21.3.2813

[45] Chirsanova, A., Reșitca, V., Siminiuc, R., et al. (2021) Produse Alimentare Inovative. Universitatea Tehnică a Moldovei, Chișinău, 455 p.

[46] Xu, Z.S., et al. (2021) The $\beta$-Galactosidase LacLM Plays the Major Role in Lactose Utilization of Lactiplantibacillus plantarum. LWT, 153, Article ID: 112481. https://doi.org/10.1016/j.lwt.2021.112481

[47] Hong, H., Son, Y.J., Kwon, S.H. and Kim, S.K. (2020) Biochemical and Antioxidant Activity of Yogurt Supplemented with Paprika Juice of Different Colors. Food Science of Animal Resources, 40, 613-627.

[48] Pathak, N., Rai, A.K., Kumari, R. and Bhat, K.V. (2014) Value Addition in Sesame: A Perspective on Bioactive Components for Enhancing Utility and Profitability. Pharmacognosy Reviews, 8, 147-155. https://doi.org/10.4103/0973-7847.134249

[49] Zeineb, J., et al. (2021) Co-fermentation Process Strongly Affect the Nutritional, Texture, Syneresis, Fatty Acids and Aromatic Compounds of Dromedary UF-Yogurt. Journal of Food Science and Technology, 58, 1727-1739. https://doi.org/10.1007/s13197-020-04682-1

[50] Chirsanova, A.I., Boistean, A.V., Chiseliță, N. and Siminiuc, R. (2021) Impact of Yeast Sediment Beta-Glucans on the Quality Indices of Yoghurt. Food Systems, 4, 12-18.

[51] Cichońska, P., et al. (2021) Effect of the Addition of Whole and Milled Flaxseed on the Quality Characteristics of Yogurt. Foods, 10, Article No. 2140.

https://doi.org/10.3390/foods10092140

[52] Derewiaka, D., et al. (2019) Chia Seed Oil as an Additive to Yogurt. Grasas y Aceites, 70, e302. https://doi.org/10.3989/gya.0705182

[53] Qin, X.X., et al. (2021) Influence of Sesame Flour on Physicochemical Properties of Sour Milk Drinks. Eastern-European Journal of Enterprise Technologies 3, 6-16. https://doi.org/10.15587/1729-4061.2021.234752

[54] Larson, L.M., Cyriac, S., Djimeu, E.W., Mbuya, M.N.N. and Neufeld, L.M. (2021) Can Double Fortification of Salt with Iron and Iodine Reduce Anemia, Iron Deficiency Anemia, Iron Deficiency, Iodine Deficiency, and Functional Outcomes? Evidence of Efficacy, Effectiveness, and Safety. The Journal of Nutrition, 151, 15S-28S. https://doi.org/10.1093/jn/nxaa192

[55] Aftab, N., Faraz, S., Hazari, K., Fahad, A., AlSawalhee, N., AlQedrah, A., Naqvi, S., Paulose, L., Abdelkareem, W. and El Gergawi, T. (2021) Evaluation of the Impact of Iron Deficiency Anemia during Pregnancy on Hospital Admission and Utilization of Hospital Resources in Latifa Women and Children Hospital, Dubai, UAE. Dubai Medical Journal, 4, 242-247. https://doi.org/10.1159/000516159

[56] Neves, O., Leandra, N., Marcone, A. and de Oliveira, L. (2021) Assessment of Enzymatic Hydrolysis of Lactose in Lactose-Free Milk Production-A Comparative Study Using Capillary Zone Electrophoresis and Cryoscopy. $L W T$, 138, Article ID: 110585. https://doi.org/10.1016/j.lwt.2020.110585

[57] Guvernul Republicii Moldova (2019) Hotărîre Guvernului Nr. 158 din 07-03-2019. https://www.legis.md/cautare/getResults?doc id=113282\&lang=ro

[58] Guénard-Lampron, V., et al. (2020) Relationship between Smoothing Temperature, Storage Time, Syneresis and Rheological Properties of Stirred Yogurt. International Dairy Journal, 109, Article ID: 104742. https://doi.org/10.1016/j.idairyj.2020.104742

[59] Avedzi, H., Soprovich, A., Ramage, S., Alghamdi, A., Storey, K., Johnson, J. and Johnson, S. (2020) Healthy Eating and Active Living for Diabetes-Glycemic Index 
(HEALD-GI): A Pragmatic Randomized Controlled Trial. Current Developments in Nutrition, 4, 1289. https://doi.org/10.1093/cdn/nzaa059 006

[60] Wolever, T.M.S. (2017) Yogurt is a Low-Glycemic Index Food. The Journal of nutrition, 147, 1462S-1467S. https://doi.org/10.3945/jn.116.240770

[61] Gutiérrez-Capitán, M., et al. (2019) Organoleptic Analysis of Drinking Water Using an Electronic Tongue Based on Electrochemical Microsensors. Sensors, 19, Article No. 1435. https://doi.org/10.3390/s19061435 